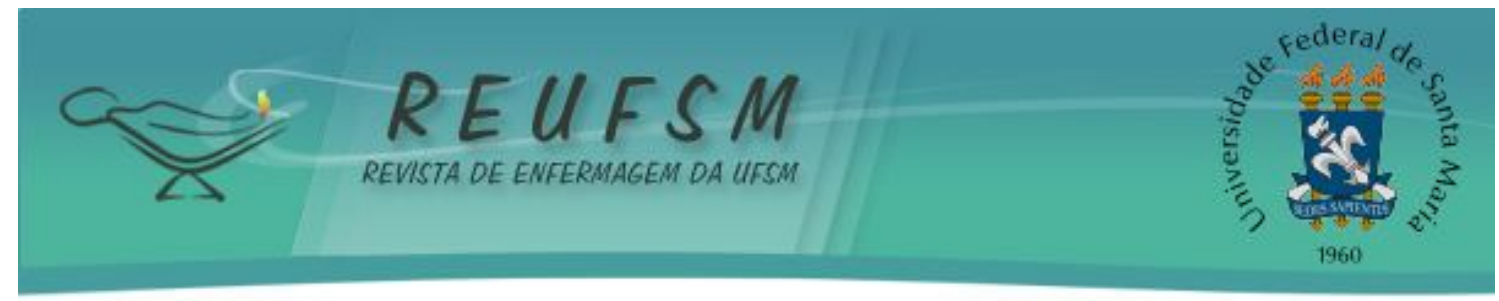

ARTIGO ORIGINAL

\title{
OCTOGENÁRIOS EM RESIDÊNCIAS UNIPESSOAIS: ENFOQUE SOBRE A QUALIDADE DE VIDA E CONDIÇÕES DE SAÚDE
}

\section{RESIDENCES IN OCT OGENARIAN SOLE PROPRIETORSHIP: A FOCUS ON QUALITY OF LIFE AND HEALTH CONDITIONS}

\section{OCTOGENARIOS EN RESIDENCIAS UNIPERSONALES: ENFOQUE EN LA CALIDAD DE VIDA Y CONDICIONES DE LA SALUD}

\author{
Bruna Liége Falcade ${ }^{1}$ \\ Marinês Tambara Leite ${ }^{2}$ \\ Leila Mariza Hildebrandt ${ }^{3}$ \\ Rosane Maria Kirchner ${ }^{4}$ \\ Luiz Anildo Anacleto da Silva ${ }^{5}$ \\ Lucia Hisako Takase Gonçalves ${ }^{6}$
}

RESUMO: Pesquisa com objetivo de caracterizar o perfil, as condições de saúde e a qualidade de vida de octogenários que residem sozinhos em um município do norte do Rio Grande do Sul/Brasil. Os sujeitos foram 27 idosos de 80 anos ou mais de idade. Os dados foram levantados por meio de um instrumento com questões acerca da saúde e do WHOQOLold, com análise descritiva. Verificou-se que entre os entrevistados, há predomínio de mulheres, viúvos e baixo grau de escolaridade. Prevalência de hipertensão arterial e um elevado percentual de gerontes que não possui doenças. A qualidade de vida dos idosos é considerada média, ao ser associada a pluralidade de domínios: funcionamento sensorial, autonomia, morte e morrer, atividades, renda, vida social e relação com a família, e categorias diferentes de sujeito para sujeito. Os resultados apontam para a importância da promoção da saúde e manutenção da capacidade funcional desse estrato populacional.

Descritores: Idoso de 80 anos ou mais; Idoso; Envelhecimento; Qualidade de vida.

ABSTRACT: Research aiming to characterize the profile, the health and quality of life of octogenarians living in a town just north of Rio Grande do Sul/ Brazil. Whose people were 27 aged who is 80 years old or older. Data were collected via an instrument that contains questions about heal th status and by WHOQOL-old, with descriptive analysis. The study allowed to verify that among the interviewees, mainly women, widows and low years of schooling. The disease is prevalent hypertension, and there is a high percentage of elderly people who do not have any diseases. The quality of life of elderly in this study is media and is associated with a plurality of areas such as sensory functioning, autonomy, death and dying, activities, income, social life and family relations, different categories of people to people. The results suggest the importance of health promotion and maintenance functional capacity these population.

Descriptors: Aged 80 and over; Aged; aging; quality of life.

\footnotetext{
${ }^{1}$ Enfermeira, egressa do Curso de Enfermagem da UFSM/ CESNORS. E-mail: brunafalcade@hotmail.com.

2 Enfermeira. Doutora em Gerontologia Biomédica, docente do Departamento de Ciências da Saúde da UFSM/ CESNORS. E-mail: tambaraleite@yahoo.com.br.

3 Enfermeira. Mestre em Enfermagem Psiquiátrica, docente do Departamento de Ciências da Saúde da UFSM/ CESNORS. E-mail: leilahildbrandt@yahoo.com.br.

4 Professora. Doutora em Engenharia Elétrica- Métodos de Apoio à Decisão, docente da UFSM/CESNORS. E-mail: rosanek@smail.ufsm.br

5 Enfermeiro. Doutor em Enfermagem docente do Departamento de Ciências da Saúde da UFSM/ CESNORS. Email: luiz.anildo@yahoo.com.br.

${ }^{6}$ Enfermeira, Dra. em Enfermagem, docente da Universidade Federal de Santa Catarina - UFSC. e-mail: Ihtakase@gmail.com
} 


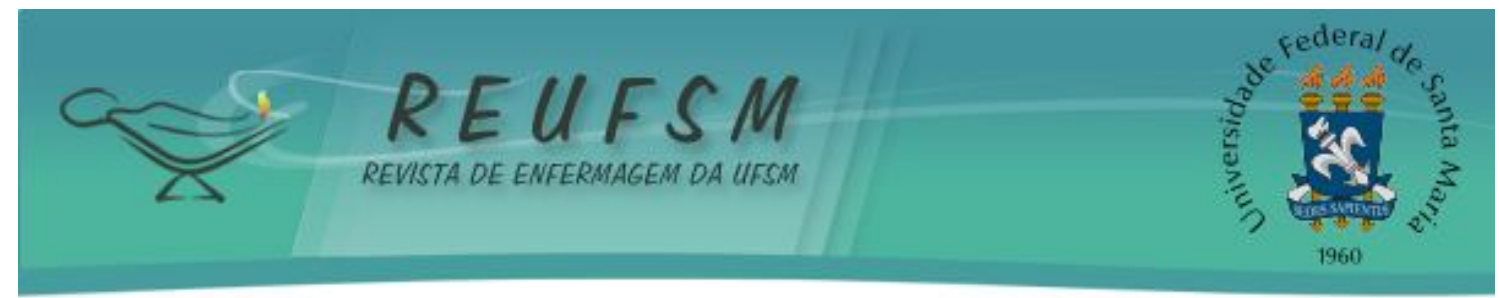

RESUMEN: Investigación con el objetivo de caracterizar el perfil, las condiciones de salud y la calidad de vida de los octogenarios que viven solo, en una ciudad al norte de Rio Grande del Sur / Brasil. Los sujetos fueron 27 ancianos de 80 años o más de edad. Los datos fueron recogidos a través de un instrumento que contiene preguntas sobre la salud y por el WHOQOL-old, con un análisis descriptivo. El estudio verificó que entre los entrevistados, predominan principalmente mujeres, viudos y bajo grado de escolaridad. La prevalencia de hipertensión arterial y al to porcentaje de ancianos que no tiene ninguna enfermedad. La calidad de vida de los ancianos es considerada mediana, cuando asociada con pluralidad de dominios: la función sensorial, la autonomía, la muerte y el morir, las actividades, la renta, la vida social y las relaciones familiares, las diferentes categorías de sujeto a sujeto. Los resultados apuntan a la importancia de la promoción de la salud y el mantenimiento de la capacidad funcional de estas poblaciones.

Descriptores: Anciano de 80 o más años; Anciano; Envejecimiento; Calidad de vida.

\section{INTRODUÇÃO}

Envelhecer é um processo natural, progressivo e irreversível, enquanto que a velhice se constitui uma etapa da vida do ser humano. O processo de envelhecimento desencadeia mudanças físicas, psíquicas e sociais nos indivíduos. Viver até os 80 anos de idade, já não é fato que surpreende, pois o prolongamento da vida vem ocorrendo desde as últimas décadas. ${ }^{1} \mathrm{O}$ segmento que mais cresceu no ano de 2000 no Brasil, foi aquele das pessoas de 75 anos ou mais de idade $(49,3 \%$ ), ou seja, o estrato de idosos mais idosos, o qual altera a composição interna do próprio grupo e revela uma diversidade de características deste segmento populacional. ${ }^{2} 0$ contingente da população da quarta idade, ou seja, de oitenta anos e mais, passou de 166 mil pessoas, em 1940, para 2,6 milhões em 2010, com estimativa de atingir cerca de seis milhões em $2030{ }^{3}$

Os esforços existentes e empreendidos para garantir uma velhice ativa e saudável, nem sempre se efetiva, pois muitos idosos experimentam fragilidade nessa fase da vida. A maior preocupação com a demanda do envelhecimento humano, deriva, comumente, do fato de encarar essa população como dependente e vulnerável. ${ }^{4}$ Porém, é importante salientar, que parte dos idosos possui independência e autonomia, residem só, em seus domicílios, ou em companhia de pessoas com as quais mantém laços de parentesco. ${ }^{5} \mathrm{~A}$ pessoa idosa que preserva sua autodeterminação, sem necessitar de auxílio ou de supervisão no desempenho das atividades diárias, pode ser considerada um geronte saudável, mesmo que possua uma ou mais morbidades crônicas. Isto se deve ao conceito de capacidade funcional, ou seja, capacidade de manter as habilidades físicas e mentais necessárias para uma vida independente e autônoma.

Ainda que haja um percentual de pessoas que envelhecem saudáveis e com autonomia, identifica-se que nessa faixa etária os idosos podem se encontrar mais frágeis e vulneráveis ao adoecimento. Nesse cenário, é entre a população idosa que ocorre a maior prevalência e incidência de doenças crônico-degenerativas que, por vezes, requer cuidados permanentes ao indivíduo. ${ }^{6} 0$ fato de morar só, nesse caso, tem sido associado a uma baixa qualidade de vida (QV), indicador de morbidade e, até mesmo, de mortalidade. ${ }^{4}$ Morar só pode, ainda, trazer para a pessoa idosa desesperança, pois não tem ninguém para compartilhar suas emoções, preocupações e esperanças.

Segundo a Organização Mundial de Saúde (OMS) a qualidade de vida de um indivíduo esta intimamente associada a sua habilidade de preservar a autonomia e a independência, em especial, na velhice. ${ }^{7}$ Qualidade de vida é um conceito amplo, contempla uma diversidade de dimensões que não se restringem às condições de saúde, sintomatologia e intervenções clínicas. ${ }^{8}$ Nesse sentido, identifica-se que há demandas de 


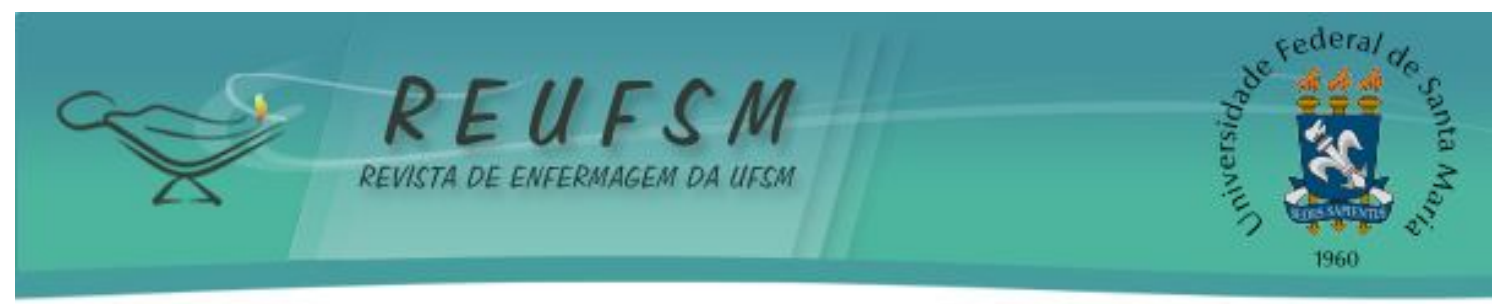

natureza social, política e econômica, pois este estrato populacional possui características e necessidades peculiares que devem ser atendidas. Além disso, devem-se direcionar ações para que esse contingente populacional viva com qualidade de vida.

Conviver com a família representa para o idoso a possibilidade de garantir a autonomia e preservar sua identidade e dignidade. Embora a família exerça um papel fundamental e importante em todas as fases da vida, observa-se que é possível encontrar idosos que residem no espaço doméstico sem a presença de familiares. São vários os modos de envelhecer, que variam conforme o gênero, a cultura, o acesso a informação, condições socioeconômicas e região em que reside. ${ }^{9}$

Embora a família seja de grande importância para os gerontes, é crescente a proporção de idosos vivendo sozinhos, tanto homens como mulheres. Viver só, para alguns gerontes, não representa abandono, descaso ou solidão. ${ }^{10}$ Determinados anciãos não têm família. Há outros cuj as famílias são pobres ou seus familiares trabalham e não podem cuidáIos. ${ }^{4}$ Neste contexto, alguns gerontes, administram sua aposentadoria, têm capacidade de argumentar sobre o que pensam e o que querem de suas vidas, ou sej a, são independentes e possuem autonomia. ${ }^{5}$ A literatura atual sinaliza as características da família de idosos em ambiente domiciliar, entretanto há ainda necessidade de busca por mais conhecimentos sobre idosos que residem só, sem a presença de familiares, pois eles estão se tornando cada vez mais velhos e com necessidades particulares. Para tanto, o objetivo dessa pesquisa foi caracterizar o perfil, as condições de saúde e a qualidade de vida de octogenários que residem sozinhos, em um município do norte do Rio Grande do Sul/ Brasil.

\section{MÉTODO}

Pesquisa de caráter interinstitucional, exploratória-descritiva, de natureza diagnóstico-avaliativa e cujos sujeitos foram idosos de 80 anos ou mais de idade. Trata-se de um subproj eto nominado "A dinâmica familiar de idosos mais idosos de Palmeira das Missões-RS/Brasil: o convívio e cuidados na quarta idade", que integra o projeto multicêntrico intitulado: DIFAl - A dinâmica da família de idosos mais idosos: o convívio e cuidados na quarta idade, que foi aprovado sob no 051/08, pelo Comitê de Ética em Pesquisa da Universidade Federal de Santa Catarina.

Participaram deste estudo todos os 27 idosos octogenários que residem sozinhos, no ambiente doméstico, na área urbana do município. A amostragem do tipo intencional foi constituída com o auxílio dos agentes comunitários de saúde, vinculados as unidades básicas de saúde, os quais detêm as informações da população adscrita a sua área de atuação. 0 participante da pesquisa voluntariou-se ao estudo, assinou o Termo de Consentimento Livre e Esclarecido, se disponibilizou a ser entrevistado no domicílio e encontrava-se em condição de responder às perguntas. Os dados foram levantados por meio de um instrumento que continha questões acerca do estado de saúde e de variáveis sócio-demográficas do idoso e por meio do WHOQOL-old. Este instrumento é composto por 24 questões que avaliam seis facetas: Funcionamento do Sensório (FS); Autonomia (AUT); Atividades Passadas, Presentes e Futuras (PPF); Participação Social (PSO); Morte e Morrer (MEM); Intimidade (INT). Cada uma das facetas possui 4 itens, que pontuam de 1 a 5 , assim para cada faceta, o escore dos valores possíveis oscila de 4 a 20. Os escores das seis facetas ou os valores dos 24 itens do módulo WHOQOL-old podem ser combinados para produzir um escore geral, para a qualidade de vida em adultos idosos, denotado como o escore total do módulo WHOQOL-old. ${ }^{11}$ Destacase que neste instrumento os itens que expressam seus valores negativamente, foram recodificados - escore reverso. Para o cruzamento entre faixa etária, gênero e utilização de medicamentos, corte no escore geral convencionado foi menos que 3 (menor qualidade de vida) e igual ou maior que 3 (maior qualidade de vida). 


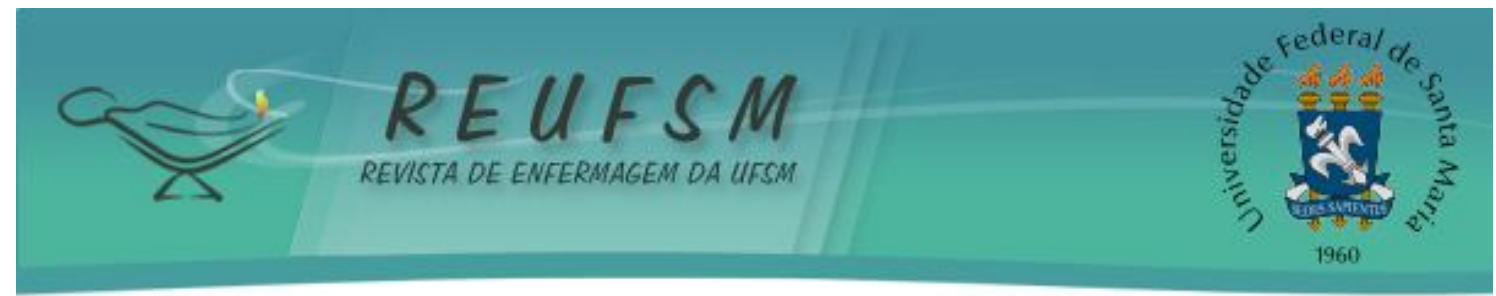

A análise descritiva da pontuação das facetas do WHOQOL-old foi realizada por meio do cálculo de médias e desvio padrão. Para essa etapa foi utilizado o software Statistical Package for Social Science (SPSS) 10.0 for Windows.

\section{RESULTADOS}

Dos participantes da pesquisa, 18 são mulheres $(66,67 \%)$ e 9 são homens (33,33\%), logo, há predomínio de mulheres. A idade da população entrevistada variou de 80 a 89 anos, média de 83,55 anos. No que se refere a escolaridade, 16 entrevistados $(59,25 \%)$ frequentaram até a 4a série do ensino formal e 11 (40,75\%) não possuem nenhuma escolaridade, como pode ser observado na Tabela 1.

Tabela 1: Distribuição da pontuação obtida pelos idosos no WHOQOL-old, segundo idade, gênero, escolaridade e medicamentos utilizados, 2010.

\begin{tabular}{lllll}
\hline & \multicolumn{5}{c}{ Média do Escore total } \\
\hline Idade & & $<3(\%)$ & $\geq 3(\%)$ & Total $(\%)$ \\
\hline Gênero & 80 a 84 & $6(22,2)$ & $13(48,1)$ & $19(70,4)$ \\
& 85 a 89 & $3(11,1)$ & $5(18,5)$ & $8(29,6)$ \\
\hline Escolaridade & Feminino & $7(25,9)$ & $11(40,7)$ & $18(66,7)$ \\
& Masculino & $2(7,4)$ & $7(25,9)$ & $9(33,3)$ \\
\hline \multirow{4}{*}{ Medicamentos utilizados } & Nenhuma & $4(14,8)$ & $7(25,9)$ & $11(40,7)$ \\
& Até a 4 $4^{\text {a série }}$ & $5(18,5)$ & $11(40,7)$ & $16(59,3)$ \\
& Nenhum & $1(3,7)$ & $9(33,3)$ & $10(37,0)$ \\
& Um & $3(11,1)$ & $3(11,1)$ & $6(22,2)$ \\
& Dois & $1(3,7)$ & $3(11,1)$ & $4(14,8)$ \\
& Três & $2(7,4)$ & $1(3,7)$ & $3(11,1)$ \\
& Quatro & $1(3,7)$ & $1(3,7)$ & $2(7,4)$ \\
& Cinco & - & $1(3,7)$ & $1(3,7)$ \\
Total & Seis & $1(3,7)$ & - & $1(3,7)$ \\
\hline
\end{tabular}

Considerando as médias dos escores totais, na pontuação obtida pelos idosos no WHOQOL-old, verificou-se que nas variáveis idade, independente da faixa etária, teve um percentual maior de idosos com média superior a 3. Este resultado, também ocorre independente do genero e da escolaridade, de forma similar. Cabe ressaltar que do total de idosos $66,7 \%$ tem escore superior ou igual a 3, isto é, uma qualidade de vida maior.

A maioria dos entrevistados é viúvo (81,49\%) e o tempo de viuvez variou de 15 dias a 40 anos. Há predomínio de idosos que professam uma crença religiosa, com destaque para a católica (59,25\%). O número de filhos variou de nenhum a 16, com média de 6,22 filhos.

Quanto as condições de saúde, 51,85\% informaram que são hipertensos, 11,11\% apresentam cardiopatia, 7,40\% possuem osteoporose, uma pequena parcela tem diabetes melitus, apresentam sequelas de acidente vascular cerebral (AVC) e se dizem portadores de câncer. Vale destacar que 33,33\% dos idosos autodeclararam não possuir enfermidades. A medicação mais utilizada pertence a classe dos antihipertensivos, sendo que 37,03\%não utilizam medicação.

Com relação a qualidade de vida, os dados evidenciam que os octogenários apresentam valores que variam de médio para bom nas facetas funcionamento sensorial de $3,25 \pm 0,72$, autonomia de $3,53 \pm 0,39$, atividades passadas, presentes e futuras de $3,24 \pm 0,65$ e na participação social de 


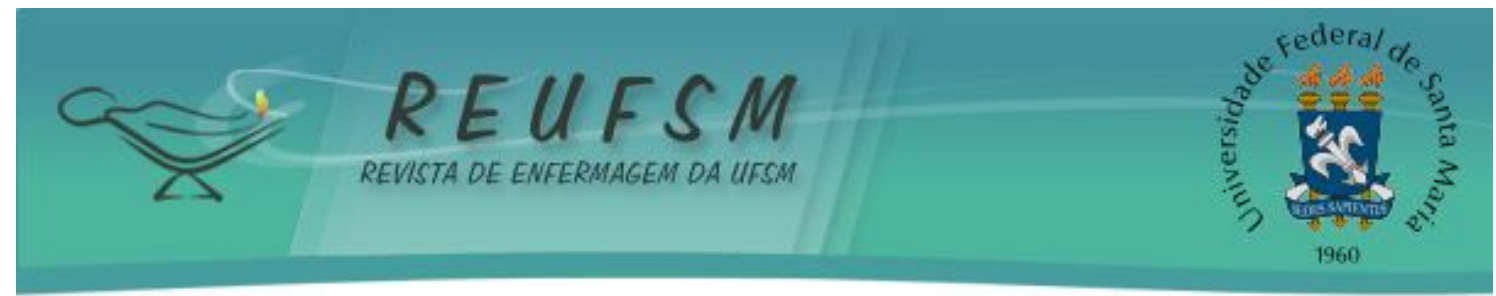

$3,09 \pm 0,73$. Na faceta morte e morrer o valor médio obtido foi de 4,02 $\pm 1,00$, sendo este o maior, dentre

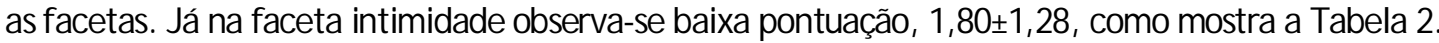

Tabela 2: Estatística descritiva da pontuação das facetas do WHOQOL-old, 2010.

\begin{tabular}{|c|c|c|c|c|c|}
\hline Facetas & & $\mathrm{Li}$ & LS & $\bar{X} \pm S$ & $(\bar{X} \pm S)^{*}$ \\
\hline $\begin{array}{l}\text { Funcionamento do } \\
\text { sensório }\end{array}$ & $\begin{array}{l}\text { Até que ponto perdas como, por } \\
\text { exemplo, audição, visão, paladar, } \\
\text { olfato, tato, afetam a vida diária } \\
\text { Até que ponto a perda nos órgãos dos } \\
\text { sentidos afeta a capacidade de } \\
\text { participar em atividades } \\
\text { O funcionamento dos sentidos afeta a } \\
\text { capacidade de interagir com outras pessoas } \\
\text { Autoavaliação do funcionamento dos sentidos }\end{array}$ & $\begin{array}{l}2 \\
2 \\
1\end{array}$ & 5 & $\begin{array}{l}3,41 \pm 0,80 \\
3,00 \pm 0,83\end{array}$ & $\begin{array}{l}3,25 \pm 0 \\
72\end{array}$ \\
\hline Autonomia & $\begin{array}{l}\text { Liberdade para tomar suas próprias decisões } \\
\text { Até que ponto você sente que } \\
\text { controla o seu futuro } \\
\text { As pessoas ao redor respeitam a liberdade } \\
\text { Fazer coisas que gosta de fazer }\end{array}$ & $\begin{array}{l}3 \\
2\end{array}$ & $\begin{array}{l}5 \\
4\end{array}$ & $\begin{array}{l}3,85 \pm 0,46 \\
3,22 \pm 0,80 \\
3,74 \pm 0,53 \\
3,30 \pm 0,78\end{array}$ & $\begin{array}{l}3,53 \pm 0 \\
39\end{array}$ \\
\hline Morte e morrer & $\begin{array}{l}\text { Preocupação com a maneira pela qual } \\
\text { irá morrer } \\
0 \text { quanto tem de medo de não poder } \\
\text { controlar a sua morte } \\
0 \text { quanto tem medo de morrer } \\
0 \text { quanto teme sofrer dor antes de } \\
\text { morrer }\end{array}$ & $\begin{array}{l}2 \\
2 \\
1\end{array}$ & $\begin{array}{l}5 \\
5\end{array}$ & $\begin{array}{l}4,15 \pm 1,06 \\
4,19 \pm 1,04 \\
4,26 \pm 0,98 \\
3,48 \pm 1,37\end{array}$ & $\begin{array}{l}4,02 \pm 1 \\
00\end{array}$ \\
\hline $\begin{array}{l}\text { Atividades passadas, } \\
\text { presentes e futuras }\end{array}$ & $\begin{array}{l}\text { Até que ponto está satisfeito com as } \\
\text { oportunidades para continuar } \\
\text { alcançando outras realizações na vida } \\
0 \text { quanto sente que recebeu o } \\
\text { reconhecimento que merece na vida } \\
\text { Quão satisfeito está com aquilo que } \\
\text { alcançou na vida } \\
\text { Quão feliz está com as coisas que } \\
\text { pode esperar daqui para frente }\end{array}$ & $\begin{array}{l}1 \\
2 \\
2\end{array}$ & 4 & $\begin{array}{l}3,19 \pm 0,74 \\
2,85 \pm 0,99 \\
3,52 \pm 0,70 \\
3,41 \pm 0,69\end{array}$ & $\begin{array}{l}3,24 \pm 0 \\
65\end{array}$ \\
\hline Participação social & $\begin{array}{l}\text { Até que ponto sente que tem o } \\
\text { suficiente para fazer em cada dia } \\
\text { Quão satisfeito está com a maneira } \\
\text { com a qual usa o seu tempo } \\
\text { Quão satisfeito está com o nível de atividade } \\
\text { Quão satisfeito está com as oportunidades } \\
\text { que tem para participar de atividades da } \\
\text { comunidade }\end{array}$ & $\begin{array}{l}2 \\
2 \\
2 \\
2\end{array}$ & $\begin{array}{l}4 \\
4\end{array}$ & $\begin{array}{l}3,04 \pm 0,76 \\
3,22 \pm 0,80 \\
3,07 \pm 0,78 \\
3,04 \pm 0,90\end{array}$ & $\begin{array}{l}3,09 \pm 0 \\
73\end{array}$ \\
\hline Intimidade & $\begin{array}{l}\text { Até que ponto tem sentimento de } \\
\text { companheirismo na vida } \\
\text { Até que ponto sente amor na vida } \\
\text { Até que ponto temoportunidades para amar } \\
\text { Até que ponto tem oportunidades } \\
\text { para ser amado }\end{array}$ & $\begin{array}{l}1 \\
1 \\
1\end{array}$ & $\begin{array}{l}4 \\
5 \\
5\end{array}$ & $\begin{array}{l}1,70 \pm 1,17 \\
1,81 \pm 1,30 \\
1,85 \pm 1,38 \\
1,81 \pm 1,33\end{array}$ & $\begin{array}{l}1,80 \pm 1 \\
28\end{array}$ \\
\hline Escore total & & 1 & 5 & & $\begin{array}{l}3,15 \pm 0, \\
51\end{array}$ \\
\hline
\end{tabular}

Li=Limite inferior; Ls=Limite superior; $\bar{X} \pm S=$ Média \pm Desvio padrão; *Total da faceta 


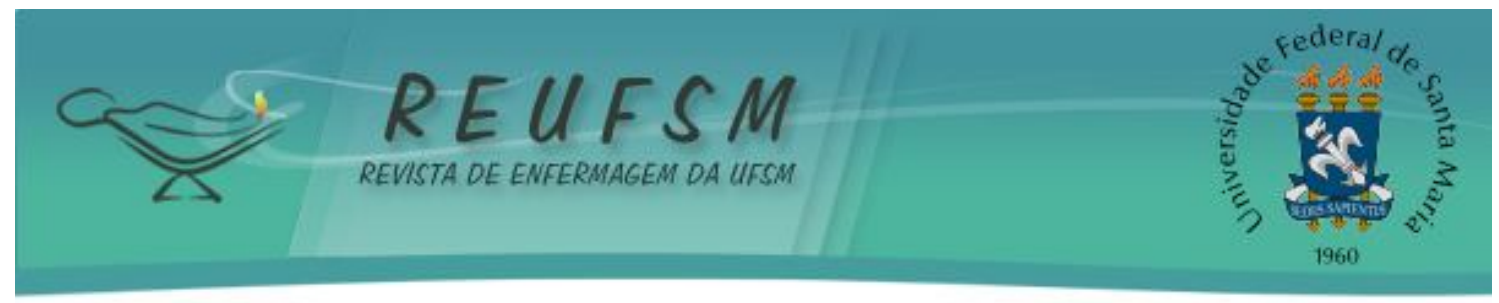

DISCUSSÃO

Os dados sociodemográficos deste estudo evidenciam predominância do sexo feminino. Este fato já era esperado, uma vez que o censo do IBGE aponta o maior número de mulheres em relação aos homens, numa proporção de $55,9 \%$ e $44,1 \%$ respectivamente no ano de $2003 .{ }^{12}$ Além disso, a expectativa de vida a partir dos 60 anos aumentou, no período de 1999 a 2003, em todas as faixas de idade, porém as mulheres têm maior tempo de vida do que os homens. No Brasil, em 2006, a expectativa de vida de pessoas com 60 anos ou mais era de 19, 3 anos para os homens e de 22,4 para as mulheres e entre os idosos de 80 anos ou mais, era de 8,9 e 9,8 anos, respectivamente. A proporção de mulheres morando sozinhas foi maior do que a de homens, que residiam mais com o cônjuge e os filhos ou somente com o cônjuge. ${ }^{13}$

No que se refere a escolaridade, 59,25\% frequentaram até a 4a série do ensino formal e $40,75 \%$ não possuem nenhuma escolaridade, o que corrobora com uma pesquisa, na qual $63,25 \%$ dos idosos entrevistados são analfabetos. ${ }^{14}$ Os idosos que residem em domicílio coletivo apresentam em relação aos demais grupos populacionais, uma maior proporção de analfabetos, seguidos dos idosos sozinhos e daqueles que não são chefes nem cônjuges. ${ }^{15}$ Estudo realizado, identificou que entre os idosos investigados houve predominância daqueles que não sabiam ler e escrever, além do número reduzido do tempo de escolarização. Esta condição se deve as dificuldades, no passado, de acesso a educação, em especial das mulheres. ${ }^{16}$

Constata-se que a maioria é viúvo, em estudo similar, $46,15 \%$ dos idosos investigados eram viúvos. ${ }^{14}$ Cruzando essa informação com os dados do Whoqol-old, o que chama atenção é a faceta intimidade, que analisa a capacidade de ter relacionamentos pessoais e íntimos, a média do escore alcançou apenas 1,80 com desvio padrão de 1,28. Este valor indica que nesta faceta os idosos possuem uma baixa qualidade de vida. Esta condição pode estar associada ao fato de os idosos deste estudo serem majoritariamente viúvos.

Há predomínio de idosos que professam uma crença religiosa, assim como em outros estudos, no qual se observa um alto grau de religiosidade entre os idosos. ${ }^{15}$ Quanto as condições de saúde, a maior parte dos entrevistados informaram que são hipertensos. Em estudo similar, destaca-se que uma das patologias mais comum relatada pelos idosos entrevistados foi a hipertensão arterial. ${ }^{14}$ As doenças crônicas são comuns entre idosos desta faixa etária e se encontram mais frequentemente entre as mulheres, uma vez que buscam mais atendimento à saúde e têm maior probabilidade de ter o diagnóstico médico. ${ }^{17} \mathrm{~A}$ medicação mais utilizada pertence a classe dos antihipertensivos, assim como em estudo onde a maioria dos idosos faz uso de medicação controlada, sendo o antihipertensivo a medicação mais utilizada. ${ }^{14}$

Vale destacar que 33,33\% dos idosos declararam não possuir enfermidades e $37,03 \%$ não utilizam nenhum tipo de medicação. Em investigação sobre o perfil dos idosos frequentadores de grupos de convivência os resultados mostram que a maioria $(85,28 \%)$ mencionou pelo menos uma doença. A saúde foi autopercebida como boa por $51,27 \%$ e péssima para $7,11 \%$ dos gerontes. Com relação ao uso de medicamentos, $89,85 \%$ dos idosos utilizavam pelo menos uma droga, em que a indicação mais frequente foi a hipertensão arterial sistêmica $(89,84 \%)$, seguida do diabetes mellitus $(88,5 \%)$, cardiopatias $(53,1 \%)$ e osteoporose $(12,39 \%)^{18,19}$ Em relação à ausência de enfermidades, dados da presente pesquisa são similares aos encontrados na literatura, uma vez que $30,8 \%$ de idosos participantes daquele estudo também mencionaram não ter problemas de saúde. ${ }^{19}$

Ao analisar as informações relativas a pontuação dos domínios do Whoqol-old, identifica-se que na faceta funcionamento do sensório, o qual avalia a parte sensorial e 0 impacto da perda de habilidades sensoriais na qualidade de vida, a média do escore alcançou 3,25, com desvio padrão de 0,72 . Este valor indica que nesta faceta os idosos possuem uma qualidade de vida mediana. 


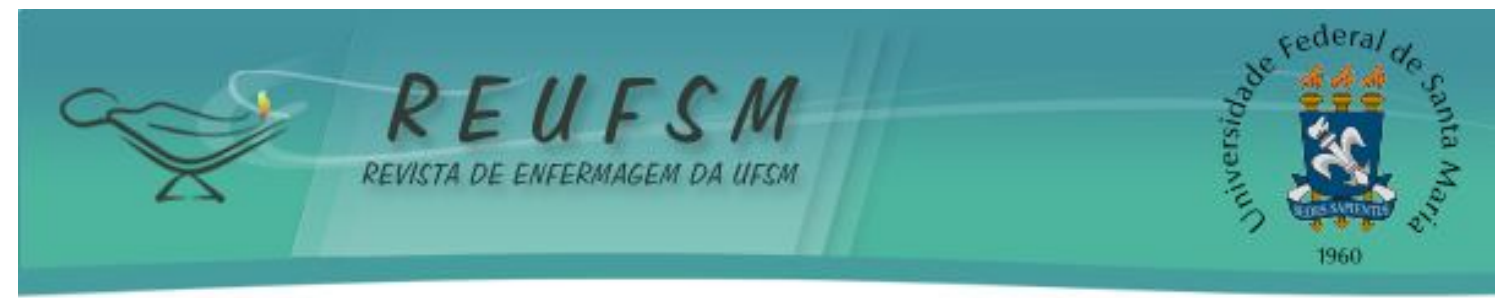

Já na faceta autonomia, em que avalia-se a independência na velhice e a capacidade ou liberdade de viver de forma autônoma e tomar decisões, a média do escore alcançou 3,53, com desvio padrão de 0,39. Este valor indica que nesta faceta os idosos possuem uma maior qualidade de vida. Aqui destaca-se a autonomia que os octogenários possuem, a capacidade de governar suas próprias vidas e morar sozinhos.

Quando nos reportamos a faceta morte e morrer, em que é possível avaliar as inquietações e temores sobre a morte e o morrer, a média do escore alcançou 4,02 com desvio padrão de 1,00. Este valor indica que nesta faceta os idosos possuem uma maior qualidade de vida e que não se preocupam com a morte ou que estão preparados para morrer. Este dado é semelhante a um estudo que associa esses resultados a questões de espiritualidade, pois os idosos crêem que a morte é certa para todos, não se deve temê-la e sim aceitá-la. ${ }^{14}$

Observa-se uma qualidade de vida mediana na faceta atividades passadas, que avalia a satisfação sobre conquistas na vida e coisas a que se anseia, a média do escore alcançou 3,24 com desvio padrão de 0,65 . Já na faceta participação social, na qual avalia-se a participação nas atividades cotidianas, especialmente na comunidade, a média do escore alcançou 3,09 com desvio padrão de 0,73 . Este valor indica que nesta faceta os idosos possuem uma menor qualidade de vida. 0 dia a dia das pessoas idosas é permeado de situações, al egres ou não, que comumente as pessoas desejam e necessitam socializar com outra pessoa. ${ }^{5}$

Assim, é importante poder contar com alguém que se disponha a escutar, dialogar e, muitas vezes, ajudar a compreender, solucionar ou mesmo aceitar os acontecimentos diários. Em se tratando de indivíduos que estão vivenciando a velhice, a necessidade de socializar os fatos corriqueiros da vida, também, faz parte de sua existência. 0 compartilhamento de emoções e sentimentos, frequentemente, ocorre entre familiares e amigos. Entretanto, muitos idosos não possuem filhos ou familiares próximos e somente contam com os amigos para interagir e dialogar, constituindo-se em uma rede de apoio. A interação social vivenciada pelos idosos colabora para o exercício de sua cidadania e, também, para que o indivíduo se sinta valorizado e inserido no meio social.

\section{CONCLUSÕES}

0 estudo possibilitou verificar que entre os idosos com 80 anos ou mais de idade que vivem sozinhos, há predomínio de mulheres, viúvos e baixo grau de escolaridade. A hipertensão arterial é a doença prevalente entre esses gerontes. Por se tratar de uma população envelhecida, chama a atenção o elevado percentual de gerontes que não possui doenças.

Verifica-se que a qualidade de vida dos idosos mais idosos deste estudo pode ser considerada de média a boa ao ser associada a uma pluralidade de domínios como: funcionamento sensorial, autonomia, morte e morrer, atividades, renda, vida social e relação com a família, e categorias diferentes de suj eito para suj eito. $O$ aspecto saúde aparece como um bom indicador de qualidade de vida. Contudo, a faceta intimidade aponta uma qualidade de vida negativa, fato esse que pode estar associado a condição conjugal dos idosos, maior parte é viúvo( $81,49 \%$, e a situação de estar residindo só no espaço doméstico.

Ressalta-se que resultados apontam a importância de intervenções em saúde com vistas a promoção da saúde e manutenção da capacidade funcional desse estrato populacional, uma vez que ter mais ou menos qualidade de vida depende, em parte, das condições de acesso aos serviços sociais e de saúde.

\section{REFERÊNCIAS}

1. Camarano AA. Os novos idosos brasileiros muito além dos 60? Rio de J aneiro: IPEA; 2004.

2. IBGE. Perfil dos idosos responsáveis pelos domicílios no Brasil 2000. Estudos e Pesquisas: Informação Demográfica e Socioeconômica, 2002. 


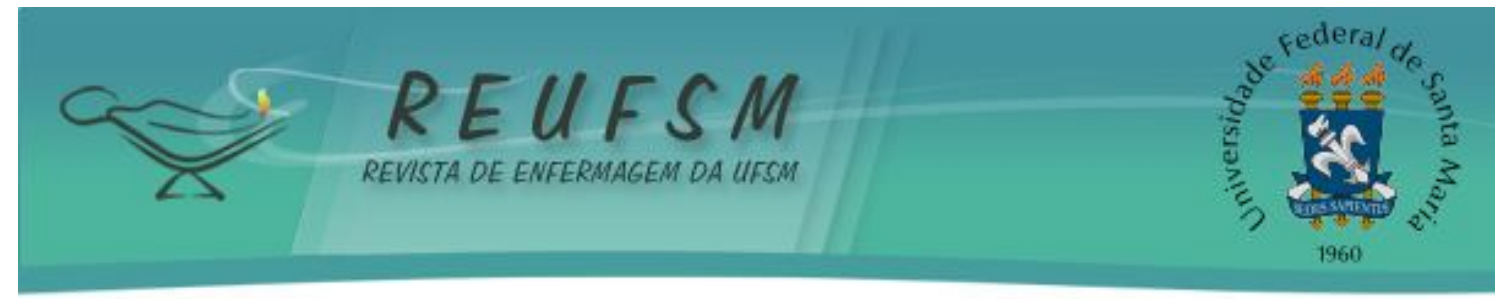

3. IBGE. Estudos e Pesquisas: informações demográficas e socioeconômicas/Indicadores sociodemográficos e de saúde no Brasil. Brasília, 2008.

4. Caldas CP. Envelhecimento com dependência: responsabilidades e demandas da família. Cad saúde pública. 2003; 19(3): 733-781.

5. Leite MT, Battisti IDE, Berlezi EM, Scheuer Al. Idosos residentes no meio urbano e sua rede de suporte familiar e social. Texto \& contexto enferm. 2008; 17(2): 250-257.

6. Paschoal SMP. Desafios da longevidade: qualidade de vida. Mundo Saúde. 2005; 29(4): 608-12.

7. Organização Mundial da Saúde. Organização Pan-Americana da Saúde. Envelhecimento ativo: uma política de saúde. Brasília (DF): OMS/ OPAS; 2005.

8. Inouye K, Pedrazzani ES, Pavarini SCl. Octogenários e cuidadores: perfil sóciodemográfico e correlação da variável qualidade de vida. Texto \& contexto enferm. 2008; 17(2): $350-7$.

9. Dallepiane LB. (Org.) Envelhecimento humano: campo de saberes e práticas em saúde coletiva. 1ae ed. Ij ui: Unijui, 2009.

10. Camarano AA. Mulher idosa: suporte familiar ou agente de mudança?. Estud av. 2003; 17(49): 35-63.

11. Fleck MPA, Chachamovich E, Trentini C. Projeto WHOQOL-OLD: método e resultados de grupos focais no Brasil. Rev saúde pública. 2003; 37(6): 793-99.

12. IBGE. Estudos e Pesquisas: informações demográficas e socioeconômicas/Indicadores sociodemográficos e de saúde no Brasil. Brasília, 2009.

13. Duarte YAO, Lebrão ML, Lima FD. Contribuição dos arranjos domiciliares para o suprimento de demandas assistenciais dos idosos com comprometimento funcional em São Paulo, Brasil. Rev panam salud publica. 2005; 17(5/6): 370-8.

14. Torres GV, et al. Qualidade de vida e fatores associados em idosos dependentes em uma cidade do interior do Nordeste. J bras psiquiatr. 2009; 58(1): 39-44.

15. Reis ALOC. Idosos em família: chefia ou dependência-determinantes socioeconômicos e demográficos. Rio de Janeiro: [s.n.], 2005. 134 p. Dissertação (Mestrado)- Curso em Estudos Populacionais e Pesquisas Sociais, 2005.

16. Pacheco RO, Santos SSC. Avaliação global de idosos em unidades de PSF. Textos Envelhecimento. 2004; 7(2): 45-61.

17. Soares MBO, et al. Características sociodemográficas, econômicas e de saúde de idosas octogenárias. Ciênc cuid saude. 2009; 8(3):452-459.

18. Borges PLC, et al. Perfil dos idosos frequentadores de grupos de convivência em Belo Horizonte, Minas Gerais, Brasil. Cad saúde pública. 2008; 24(12):2798-2808.

19. Paskulin LMG, Vianna LAC. Perfil sociodemográfico e condições de saúde autoreferidas de idosos de Porto Alegre. Rev saúde pública, 2007; 41(5):757-68.

Data de recebimento: 04/08/2011

Data de aceite: 06/09/2011

Contato com autor responsável: Marinês Tambara Leite

Endereço postal: Rua Floriano Peixoto, 776. Centro. Ijuí/ RS,

CEP: 98700-000.

E-mail: tambaraleite@yahoo.com.br 